\title{
The Effect of Center of Gravity and Anthropometrics on Human Performance in Simulated Lunar Gravity
}

\author{
Lealem Mulugeta, USRA, DSLS \\ Steven P. Chappell, Wyle Integrated Science \\ \& Engineering Group \\ Nicholas G. Skytland, Lyndon B. Johnson \\ Space Center, NASA
}




\section{Presentation Outline}

- Motivation

- Background

- Contribution

- Methods

- Results and Discussions

- Recommendations

- Conclusions 


\section{Motivation (1)}

- Revitalized interest to return to the Moon

- EVA hours to establish and operate a lunar base will greatly exceed all EVA hours logged since the beginning of human spaceflight

- ESA HUMEX study: 960 hours for a single 180 day mission (Horneck and Comet, 2006) 


\section{Motivation (2)}

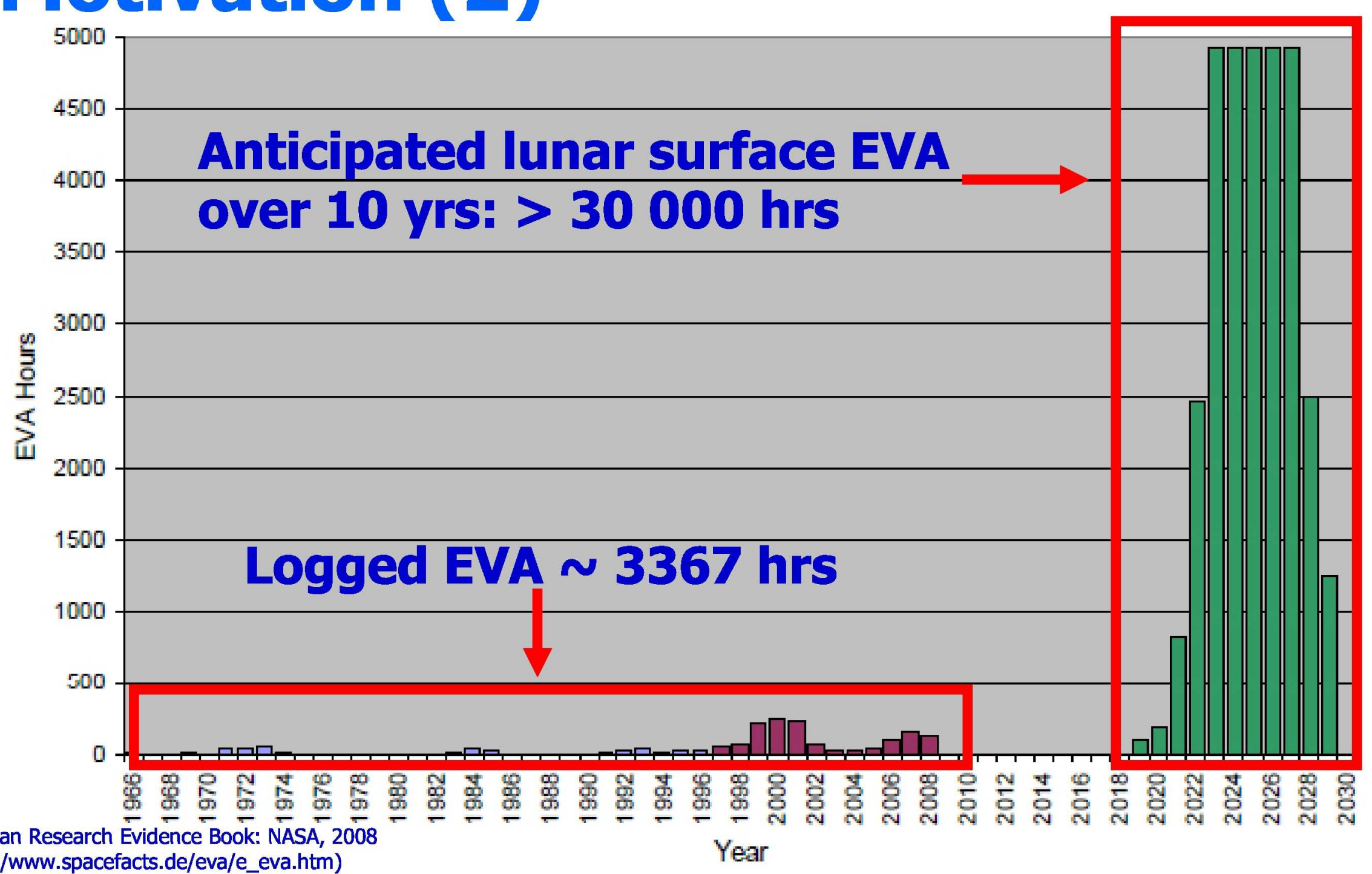

http://www.spacefacts.de/eva/e_eva.htm) 


\section{Motivation (3)}

- Tasks with highest potential to affect crewmember's safety and performance on the lunar surface are those that require EVA (ISU, 2008)

- Some Apollo mission objectives not fully met due to physical limitations the A7LB suits imposed on the crew

- Imperative to develop advanced spacesuits to allow astronauts to perform surface EVAs safely, efficiently, and effectively

- Major deficiency in Apollo suits believed to be instability caused by off-nominal CG induced by the PLSS 


\section{Motivation (4)}

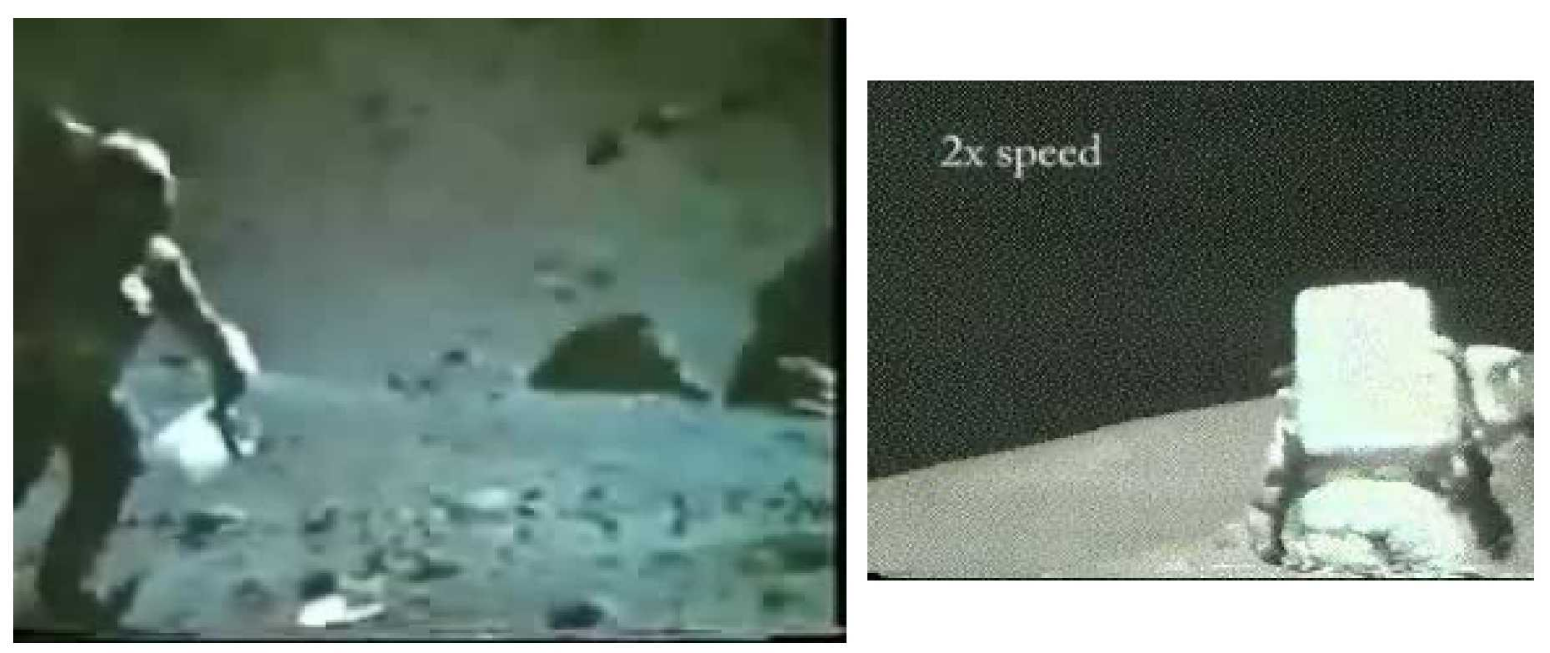

SAEAAerospace

2009-01-2561 


\section{Background (1)}

- NASA EVA Physiology, Systems and Performance (EPSP) Project at JSC has been investigating the effects of CG and other factors on astronaut performance in reduced gravity.

- A subset of the studies have been performed with the water immersion technique
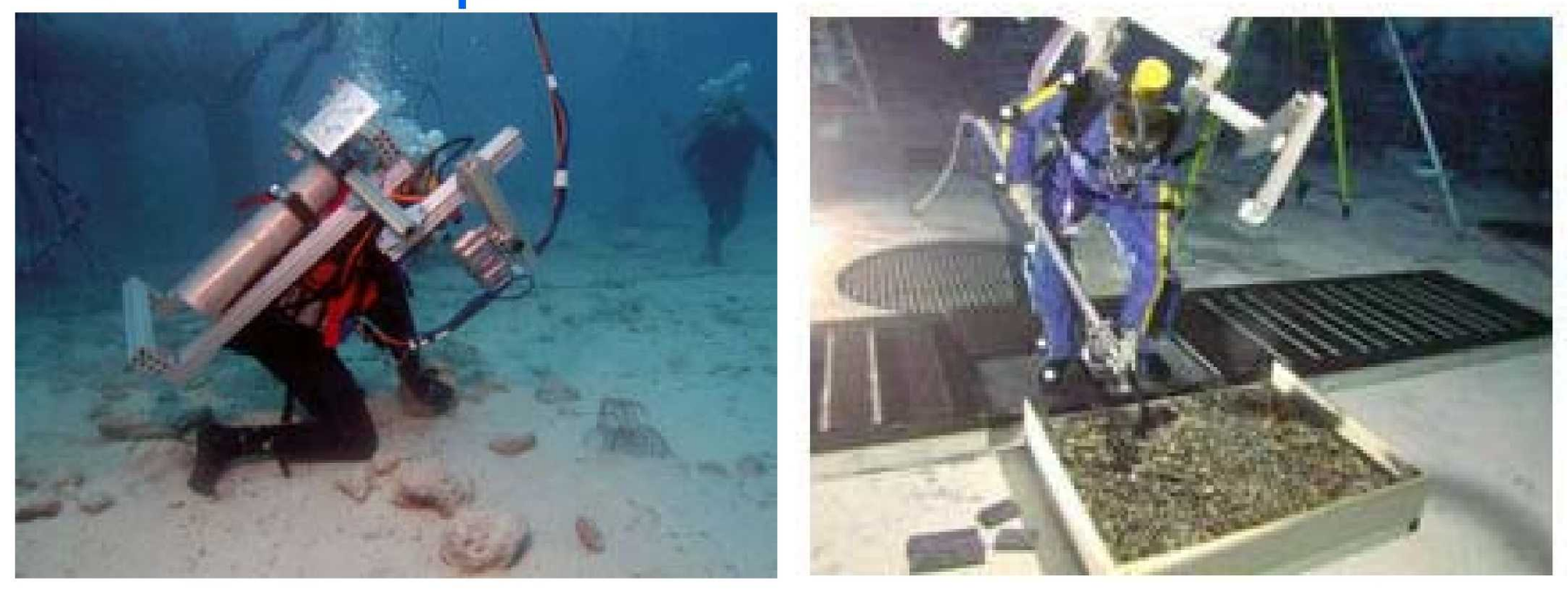


\section{Background (2)}

- Study results show correlation between CG location and performance

- However, data variability observed between subjects for prescribed CG configurations

- Hypothesis: Anthropometric differences between test subjects could be a source of the performance variability 


\section{Contribution (1)}

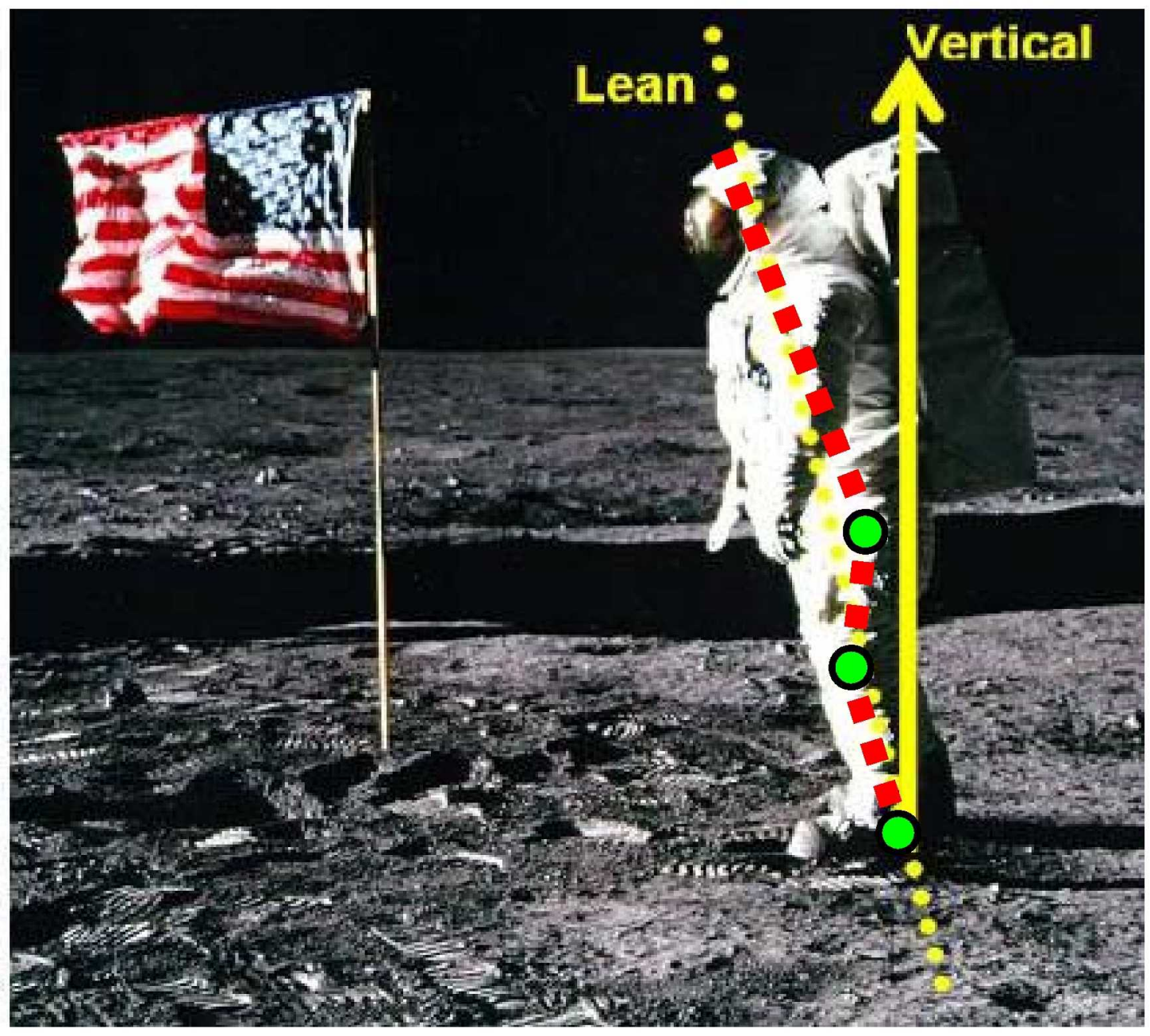

(Mulugeta, 2008)

AAFEA Aerospace

2009-01-2561 


\section{Contribution (2)}

1. Lean via rotation about the ankle

2. Knee flexion, forcing CG farther AFT of the base of support (BOS) than would be achieved by pure lean via rotation about the ankle joint

3. Hip flexion for forward displacement of the CG over the BOS

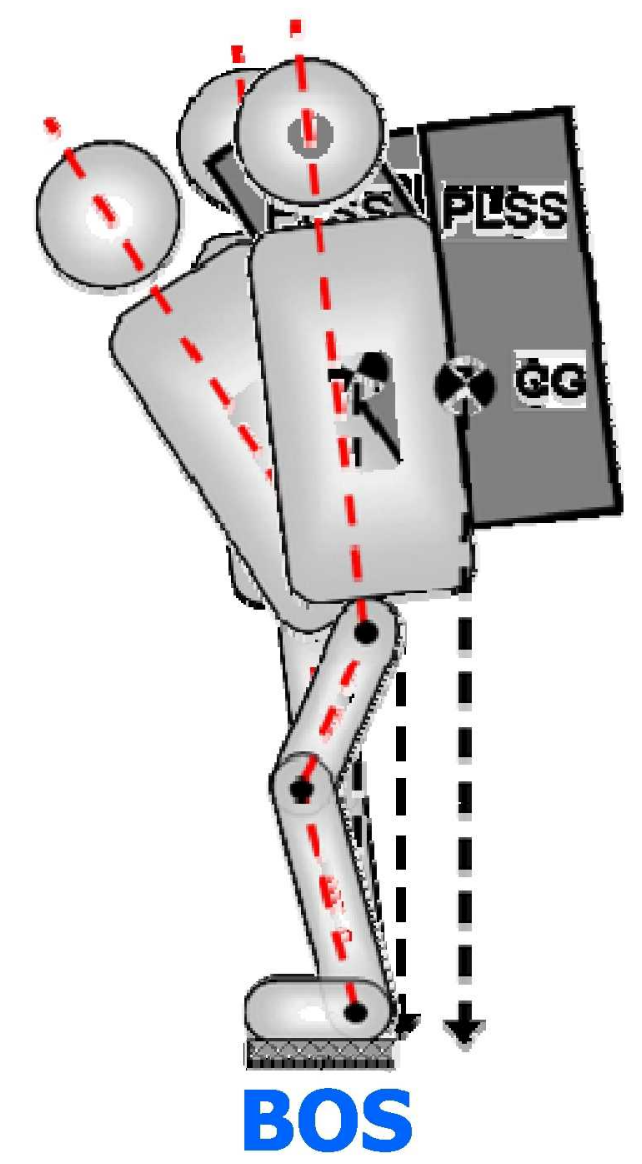

An SAE Intermational Group

2009-01-2561 


\section{Contribution (3)}

$T H R=\frac{\text { Trunk }}{\text { Height }}$

$\uparrow$ THR $\uparrow$ Performance

$T S R=\frac{\text { Thigh }}{\text { Shank }}$

$\downarrow$ TSR $\uparrow$ Performance

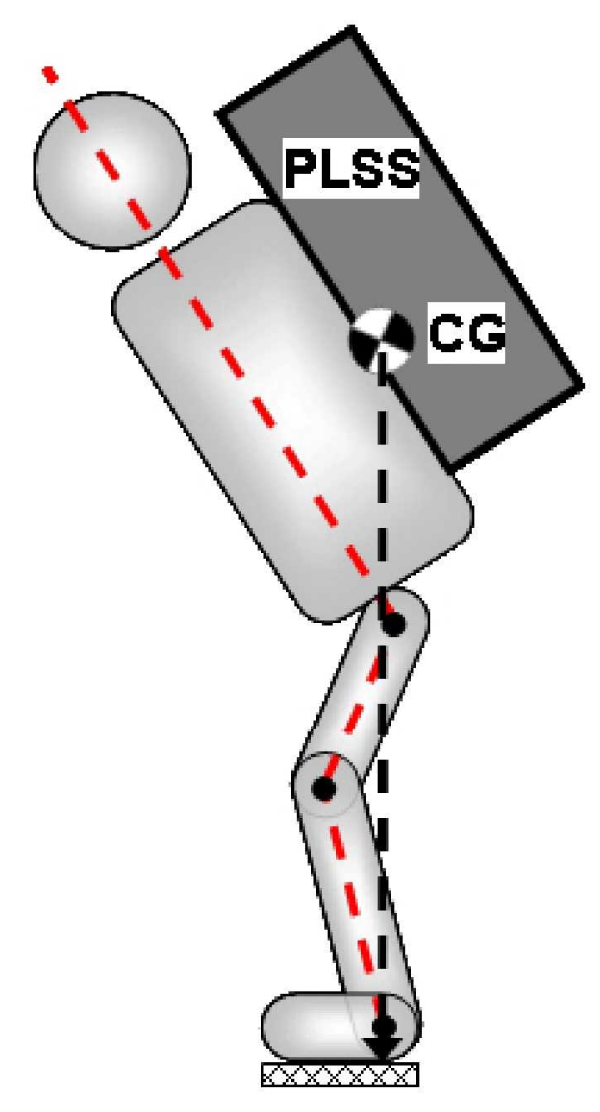

SAAEAerospace

2009-01-2561 


\section{Contribution (4): Illustrated example}

High THR $($ THR $=0.364)$

Low THR $($ THR $=0.297)$

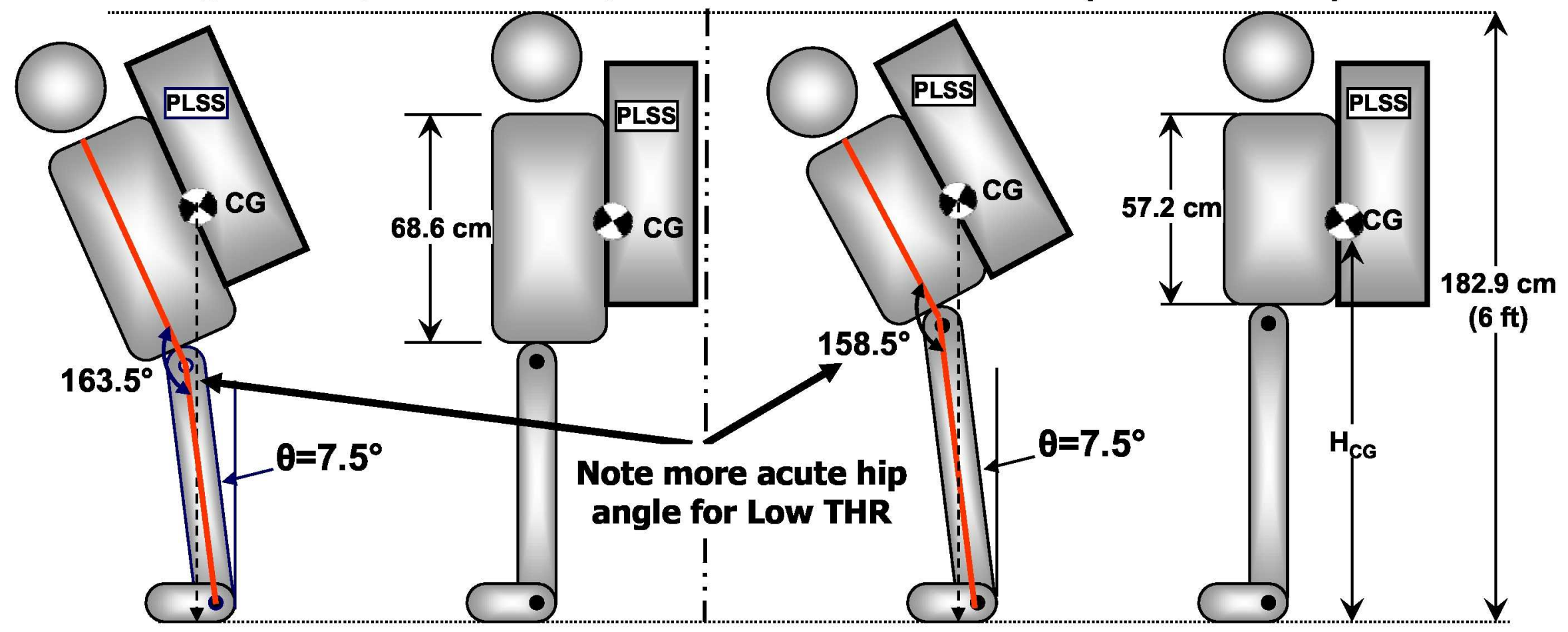

CG Compensation Upright Position CG Compensation Upright Position

\section{Assumptions of illustrative example}

- $\theta=7.5^{\circ}$ from direct measurements of figure on slide 9 (Buzz saluting flag)

- Both subjects are the same height

Q. Knee bend ignored (future studies)

- CG location the same for both subjects $\left(\mathrm{H}_{\mathrm{CG}}\right)$ 


\section{Methods: Anthropometrics \& Subjects}

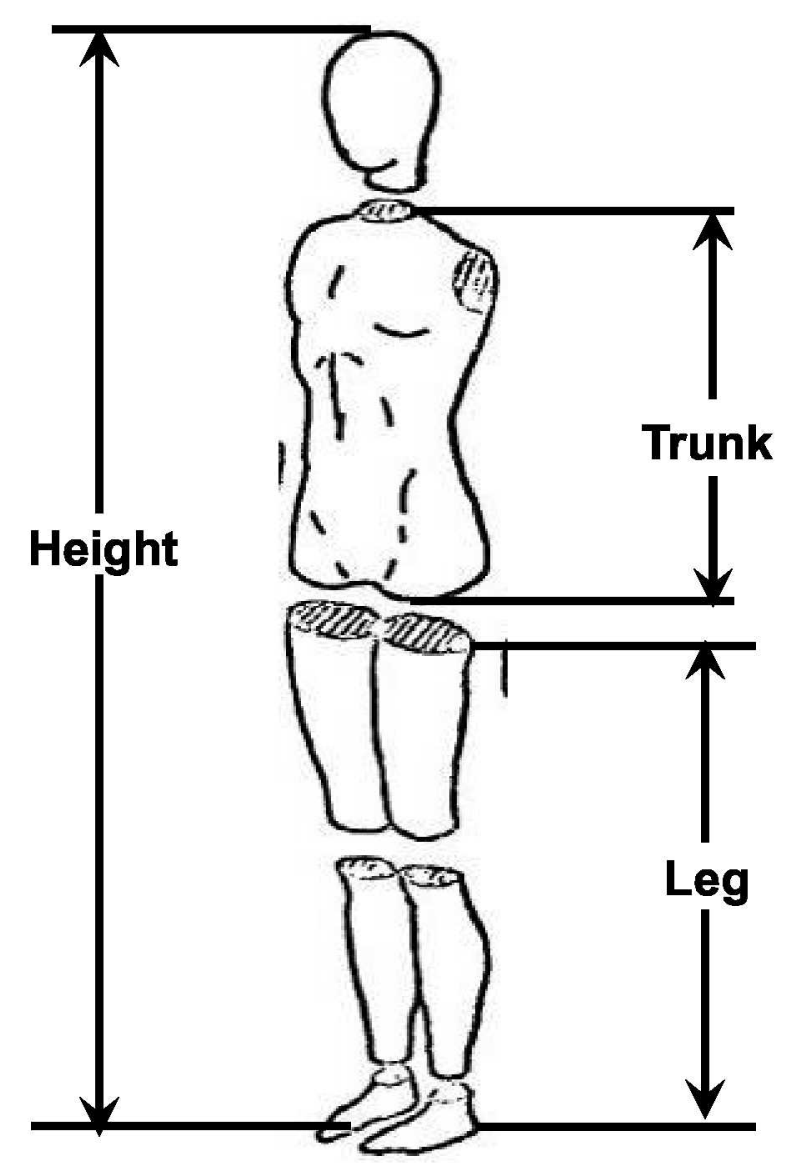

\begin{tabular}{|c|c|c|c|c|}
\hline Parameter & Mean & $\pm S D$ & Range & $\begin{array}{c}\text { Test } \\
\text { Environment }\end{array}$ \\
\hline Mass (kg) & 73.1 & 13.9 & $46.9-95.3$ & \multirow{4}{*}{ NBL + NEEMO } \\
\hline Height $(\mathrm{cm})$ & 177.2 & 7.4 & $159.5-187.1$ & \\
\hline Trunk (cm) & 72.0 & 3.8 & $65.7-77.6$ & \\
\hline THR & 0.406 & 0.010 & $0.391-0.423$ & \\
\hline Mass (kg) & 70.4 & 14.4 & $46.9-83.5$ & \multirow{4}{*}{ NBL } \\
\hline Height (cm) & 178.6 & 8.9 & $159.5-187.1$ & \\
\hline Trunk (cm) & 72.5 & 4.3 & $65.7-77.8$ & \\
\hline THR & 0.406 & 0.012 & $0.391-0.421$ & \\
\hline Mass (kg) & 75.5 & 13.8 & $56.7-95.3$ & \multirow{4}{*}{ NEEMO } \\
\hline Height $(\mathrm{cm})$ & 176.0 & 6.1 & $167.5-183.6$ & \\
\hline Trunk (cm) & 71.6 & 3.6 & $67.9-77.6$ & \\
\hline THR & 0.406 & 0.009 & $0.398-0.423$ & \\
\hline
\end{tabular}

\begin{tabular}{|l|c|}
\hline Environment & No. of Subjects \\
\hline NBL & 8 \\
\hline NEEMO & 9 \\
\hline Total & 17 \\
\hline
\end{tabular}




\section{Methods: Tasks}

\begin{tabular}{|c|c|c|c|c|}
\hline No. & Task & Task Description & NBL & NEEMO \\
\hline 1 & Preferred Ambulation & Ambulate as desired & $\mathrm{Y}$ & $\mathrm{Y}$ \\
\hline 2 & Fall-Recovery & Fall forward and get up & $\mathrm{Y}$ & $\mathrm{Y}$ \\
\hline 3 & Shoveling & Scoop a pile of gravel/sand with shovel & Y & $\mathrm{Y}$ \\
\hline 4 & Rock Lift & Pick up rock from ground with one hand & $\mathrm{Y}$ & $\mathrm{Y}$ \\
\hline 5 & Kneel-Recovery & Fall to one knee and get up & $\mathrm{Y}$ & $\mathrm{Y}$ \\
\hline 6 & Timed Walk & Walk $9 \mathrm{~m}$ with one foot always on ground & $\mathrm{Y}$ & $\mathrm{Y}$ \\
\hline 7 & Timed Jog & Traverse $9 \mathrm{~m}$ at slowest speed which both feet leave ground & $\mathrm{Y}$ & $\mathrm{Y}$ \\
\hline 8 & Timed Run & Traverse $9 \mathrm{~m}$ at fastest speed & $\mathrm{N}$ & $\mathrm{Y}$ \\
\hline 9 & Ladder Climb & Climb ladder & $\mathrm{Y}$ & $\mathrm{Y}$ \\
\hline 10 & Jumping & Jump standing in place & $\mathrm{Y}$ & $\mathrm{N}$ \\
\hline 11 & Rock Task & Transport rock between 2 locations & $\mathrm{Y}$ & $N$ \\
\hline $12 / 13$ & $\operatorname{Ramp}+/-10^{\circ}$ & Walk up/down $10^{\circ}$ slope & $\mathrm{Y}$ & $\mathbf{N}$ \\
\hline $14 / 15$ & $\operatorname{Ramp}+/-15^{\circ}$ & Walk up/down $15^{\circ}$ slope & $\mathrm{Y}$ & $\mathrm{N}$ \\
\hline $16 / 17$ & $\operatorname{Ramp}+/-20^{\circ}$ & Walk up/down $20^{\circ}$ slope & $Y$ & $\mathrm{~N}$ \\
\hline $18 / 19$ & $\operatorname{Ramp}+/-25^{\circ}$ & Walk up/down $25^{\circ}$ slope & $\bar{Y}$ & $\mathrm{~N}$ \\
\hline $20 / 21$ & $\operatorname{Ramp}+/-30^{\circ}$ & Walk up/down $30^{\circ}$ slope & $\mathrm{Y}$ & $\mathrm{N}$ \\
\hline
\end{tabular}




\section{Methods: CG Adjustment (1)}

\begin{tabular}{|l|c|c|}
\hline $\begin{array}{c}\text { CG Configuration } \\
\text { Designation }\end{array}$ & $\mathbf{X}(\mathbf{c m})$ & $\mathbf{Z}(\mathbf{c m})$ \\
\hline$\Delta$ Ideal & -0.08 & 4.1 \\
\hline ○ Baseline & -7.6 & 14.4 \\
\hline \hline High & 0.08 & 26.5 \\
\hline O Low & -0.08 & -6.6 \\
\hline OAft & -15.0 & -0.16 \\
\hline$\square$ Forward & 0.33 & -0.05 \\
\hline ○ Apollo & -9.3 & 11.9 \\
\hline O $0,0,0$ & 0 & 0 \\
\hline
\end{tabular}

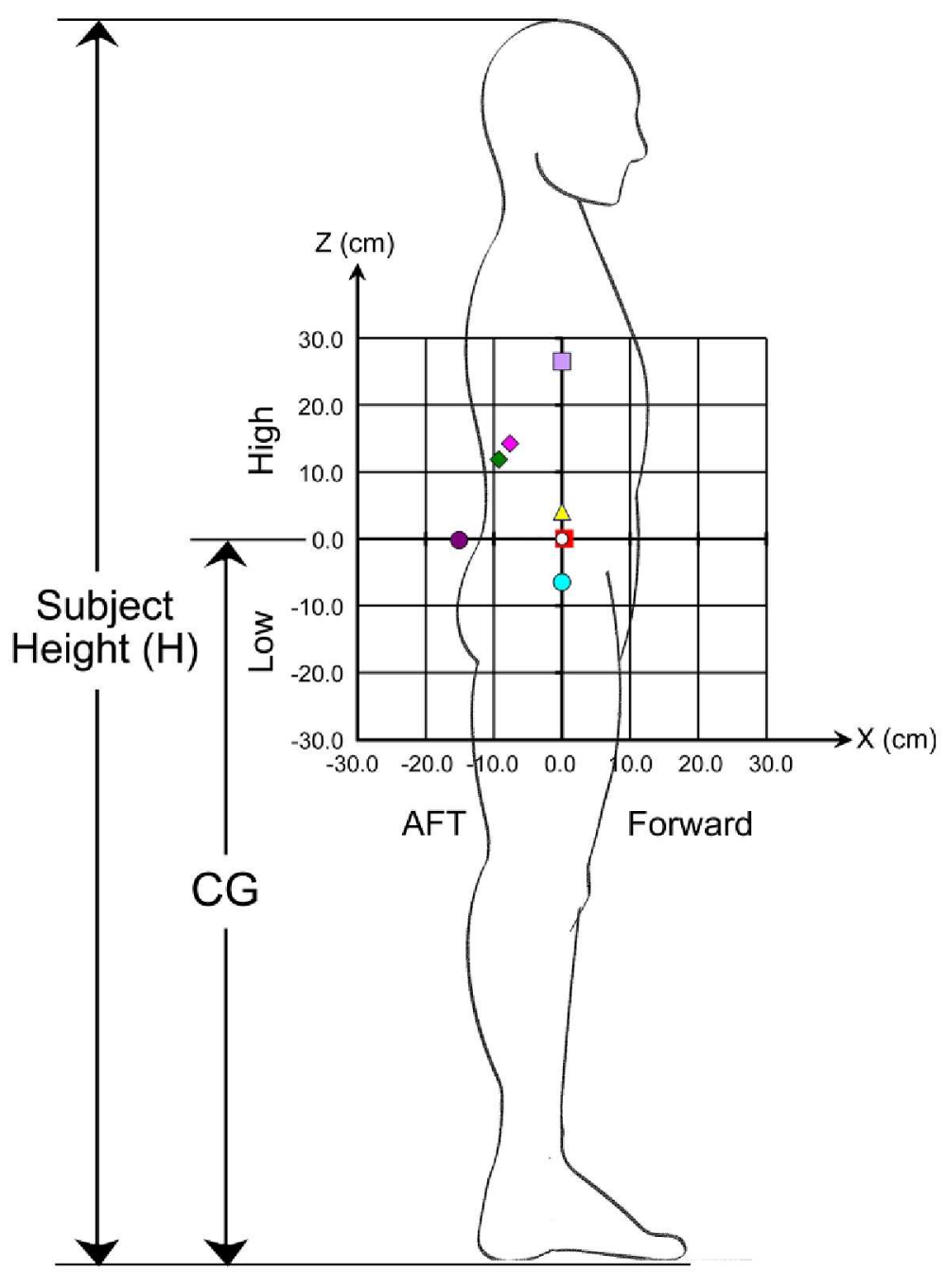




\section{Methods: CG Adjustment (2)}

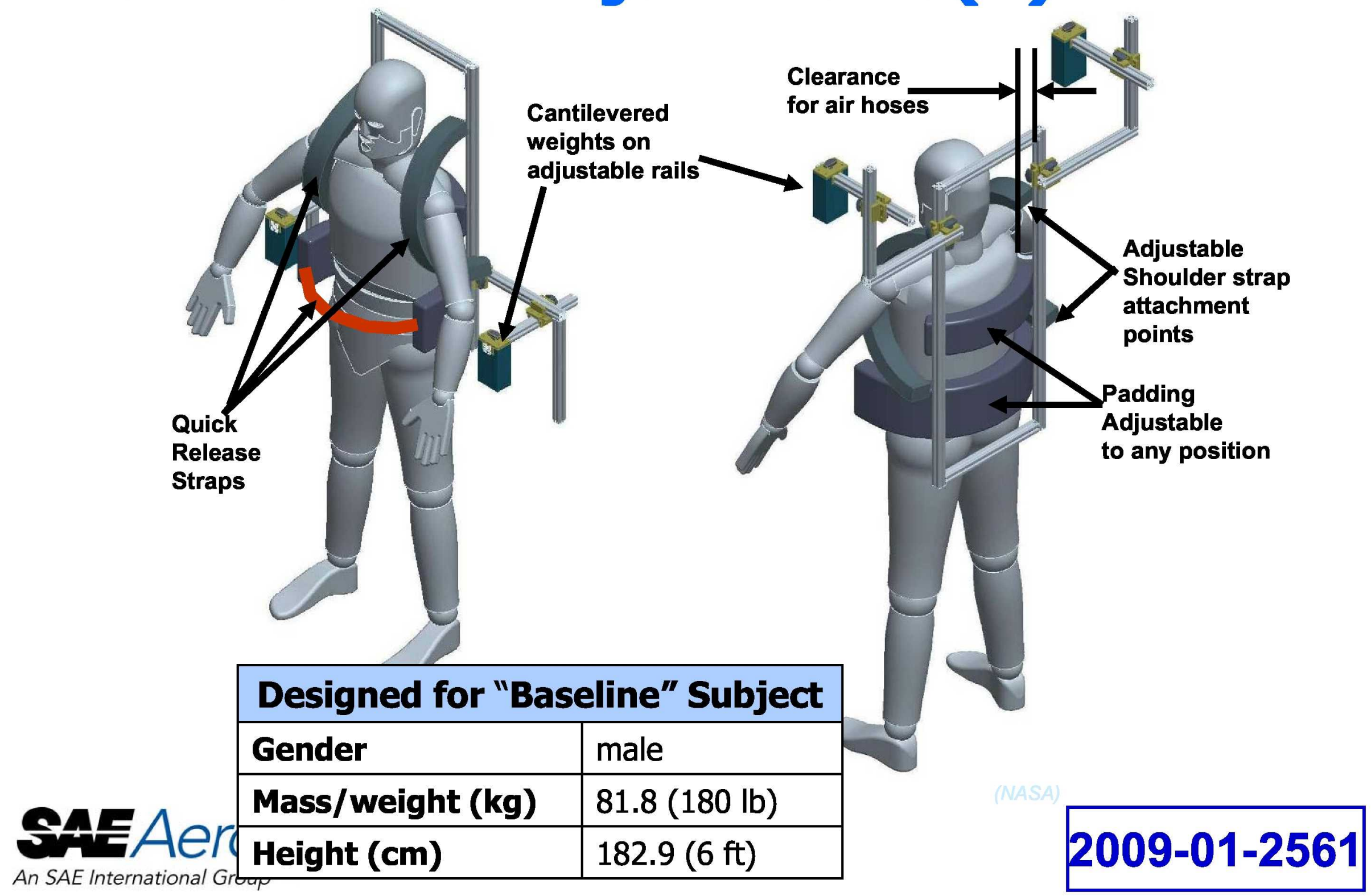




\section{Methods: Test Facilities}

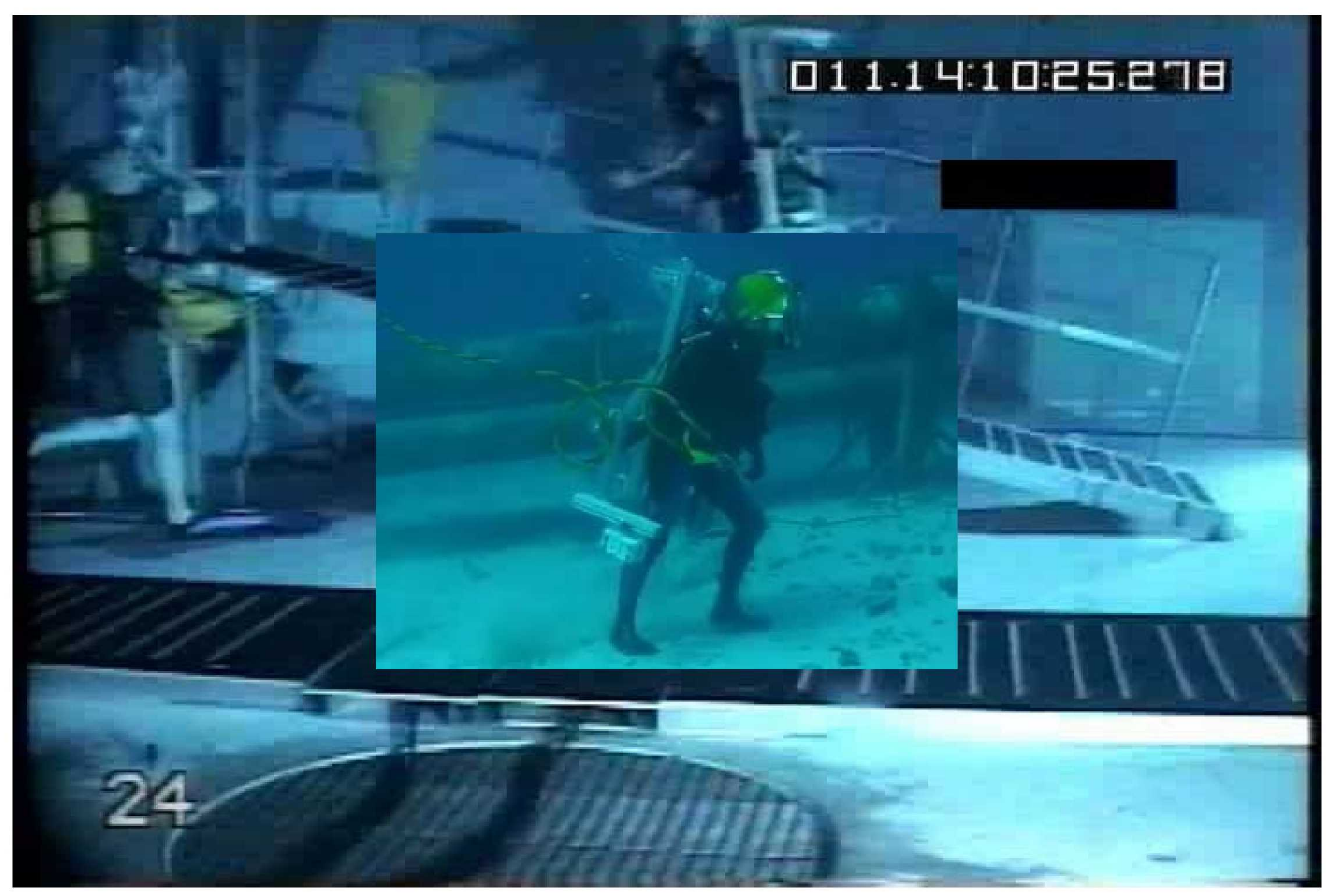

SAEEAerospace

2009-01-2561 


\section{Methods: Data Acquisition (1)}

- Subjective performance data collected using a modified Cooper-Harper (CH) Rating Scale

- Derived from the Cooper-Harper Pilot Rating Scale (CHPRS) for aircraft handling performance

- Flight experienced test subjects required for CHPRS and for any adaptations of CHPRS

- Since EPSP test subjects did not have lunar EVA experience, the modified $\mathrm{CH}$ scale employs $1-\mathrm{g}$ shirtsleeve operation as a baseline reference for performance rating

- 1 -g reference effectively qualifies subjects as experienced operators 


\section{Methods: Data Acquisition (2)}

MODIFIED COOPER-HARPER RATING SCALE

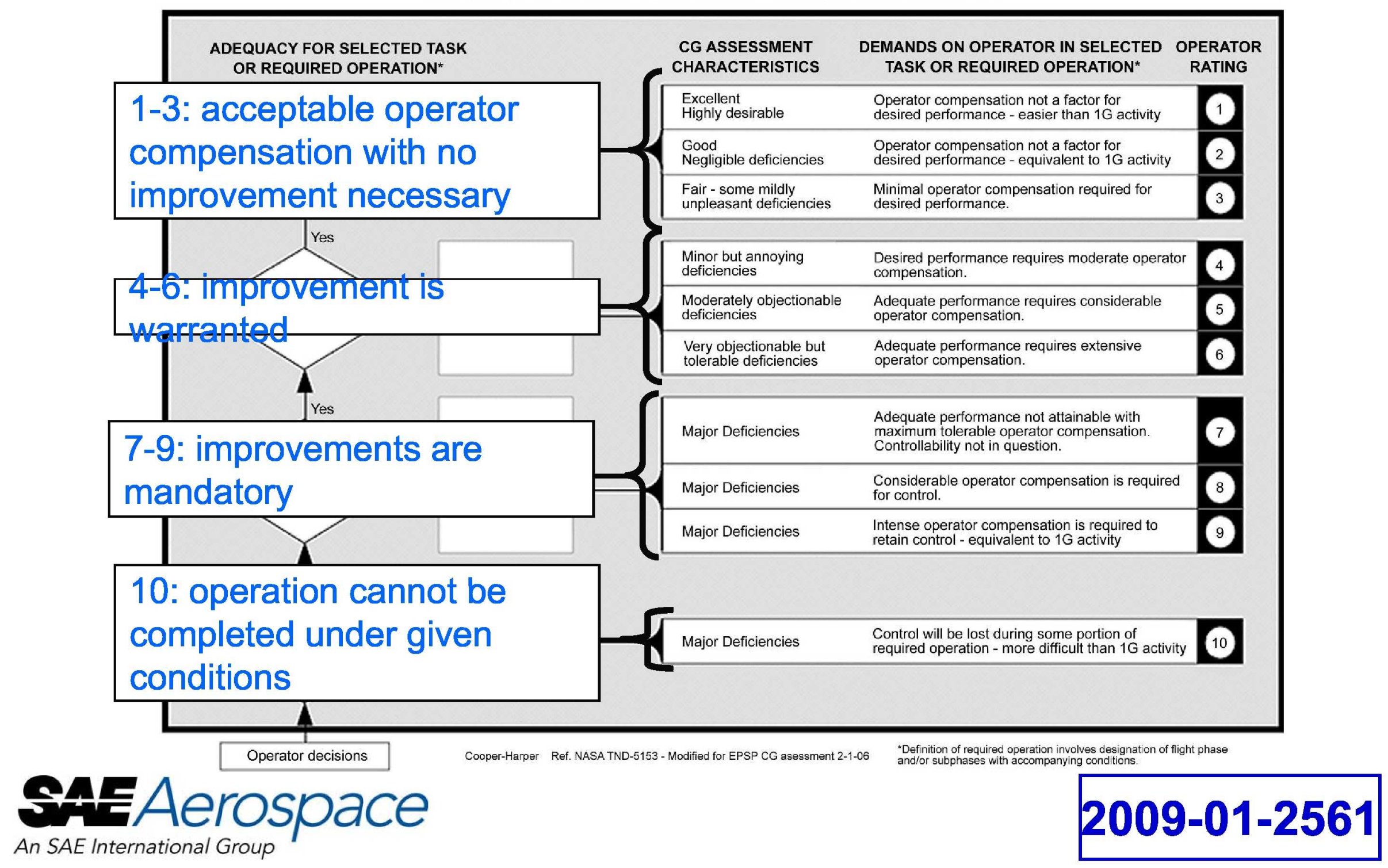




\section{Methods: Analysis (1)}

- For each task performed, linear regressions were generated using MS Excel 2003

- $\mathrm{CH}$ vs. Trunk-to-Height Ratio (THR)

- $\mathrm{CH}$ vs. Height

- $\mathrm{CH}$ vs. Trunk Length

- $\mathrm{CH}$ vs. Body Mass/Weight

- 936 regressions generated

- Primary purpose of this analysis was to guide future detailed logistic regression analyses of potential anthropometric factors that may affect performance in reduced gravity 


\section{Methods: Analysis (2)}

- Regressions interpreted strictly for slope (positive or negative)

- Magnitude of slope not considered

- Avoids subjective interpretation of results based on subjective data 


\section{Results \& Discussions: CH vs. THR (1)}

- The $\mathrm{CH}$ vs. THR results supported the hypothesized direct relationship between performance and THR

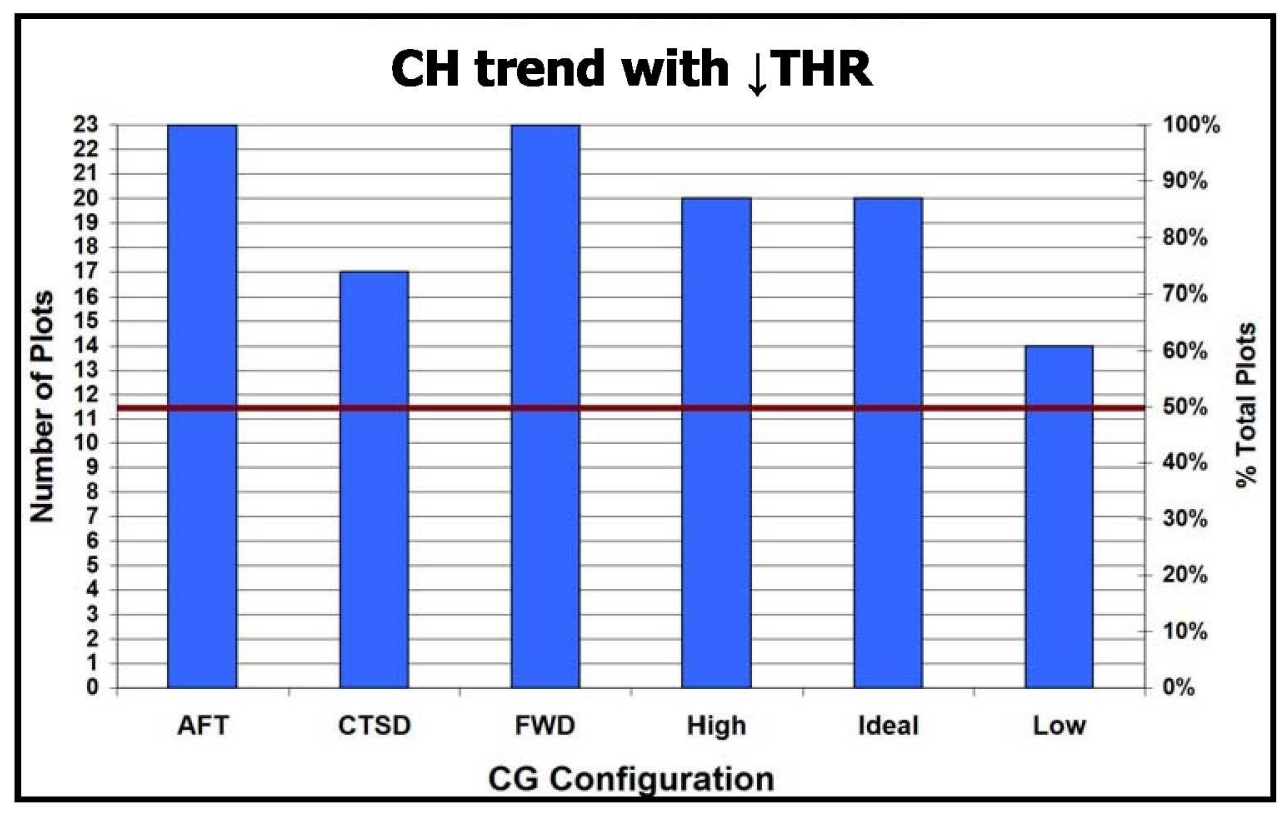

- 116 out of 138 regressions (84\%) showed increased $\mathrm{CH}$ rating with decreased $\mathrm{THR}(\uparrow \mathrm{CH}=$ decreased performance) 


\section{Results \& Discussions: CH vs. THR (2)}

- The subject with the lowest THR gave the highest $\mathrm{CH}$ rating for all tests (lowest performance)

- The test subject with the highest THR gave the lowest $\mathrm{CH}$ ratings for 17 out of the 21 tasks performed (best performance)

- Gervais and Moreau (2001) showed that higher performing marathon runners tend to run with more upright posture, and lower performing runners tend to run with a more forward trunk lean

- BWSS Martian gravity tests by Scott-Pandorf (2008) showed reduced forward lean increases back comfort and reduces energy expenditure 


\section{Results \& Discussions: CH vs. THR (3)}

- Lucia et al. (2006) compared running economy of Eritrean runners $(\mathrm{N}=7)$ and Spanish runners $(\mathrm{N}=9)$ with respect to training regime, anthropometrics and running strategy

- Eritreans' training experience, training volume, and $\mathrm{VO}_{2}$ cost of running were significantly lower

- Superior performance may, at least partly, be associated with their anthropometrics

- Lucia et al. found that Eritrean runners had lower body mass index and limb mass

- Further evaluation of the Lucia et al.'s anthropometric data was carried out in this study with regard to THR and TSR 


\section{Results \& Discussions: CH vs. THR (4)}

- Since Lucia et al. did not present the mean trunk length of the runners, upper-body to height ratio (UHR) was used in the analysis

$$
U H R=\frac{\text { Height }- \text { Leg Length }}{H e i g h t}
$$

- UHR assumed to have the same effect as THR since the trunk accounts for most of the upper-body mass and MOI

- Limited martian gravity performance data also showed direct correlation between UHR and performance (Mulugeta, 2008) 


\section{Results \& Discussions: CH vs. THR (5)}

- Mean TSR of the two groups also compared to test hypothesized inverse relationship of TSR and performance

$$
T S R=\frac{\text { Thigh }}{\text { Shank }}
$$

- Result: Eritreans had higher UHR, and lower TSR than Spaniard runners

\begin{tabular}{lcc}
\hline Anthropometric & \multicolumn{2}{c}{ Mean \pm SD } \\
\cline { 2 - 3 } Parameters & Eritreans & Spaniards \\
\hline Leg Length $(\mathrm{cm})$ & $92.3 \pm 6.5$ & $92.6 \pm 3.6$ \\
Height $(\mathrm{cm})$ & $174 \pm 8$ & $172 \pm 6$ \\
Height-Leg $(\mathrm{cm})$ & $81.7 \pm 10$ & $79.4 \pm 7$ \\
\hline Thigh Length $(\mathrm{cm})$ & $48.2 \pm 4$ & $51.9 \pm 3.6$ \\
Shank Length $(\mathrm{cm})$ & $44.1 \pm 3$ & $40.6 \pm 2.7$ \\
\hline UHR & $\mathbf{0 . 4 7 0 \pm 0 . 0 6}$ & $\mathbf{0 . 4 6 2 \pm 0 . 0 4}$ \\
TSR & $\mathbf{1 . 0 9 3} \pm \mathbf{0 . 0 1}$ & $\mathbf{1 . 2 7 8} \pm \mathbf{0 . 1 2}$ \\
\hline
\end{tabular}




\section{Results \& Discussions: CH vs. THR (6)}

- Ward et al. (1979) evaluated impact of anthropometrics on performance of master and first class Olympic weight lifters trained for the clean and jerk, and the snatch lifts

- Ward et al. noted Master lifters exhibited greater mass lifting performance and higher THR

- Further assessment of the anthro. presented by Ward et al. also showed the master lifters had lower TSR

\begin{tabular}{|c|c|c|}
\hline \multirow{2}{*}{$\begin{array}{l}\text { Anthropometric } \\
\text { Parameters }\end{array}$} & \multicolumn{2}{|c|}{ Mean \pm SD } \\
\hline & Master $(\mathbf{N}=7)$ & First Class $(\mathrm{N}=7)$ \\
\hline Trunk Length (cm) & $59.4 \pm 1.9$ & $56.4 \pm 2.2$ \\
\hline Height (cm) & $172.6 \pm 1.8$ & $172.8 \pm 7.7$ \\
\hline Thigh Length $(\mathrm{cm})$ & $36.1 \pm 3.7$ & $39.3 \pm 3$ \\
\hline Shank Length $(\mathrm{cm})$ & $36.1 \pm 1.8$ & $36.8 \pm 2.2$ \\
\hline THR & $0.344 \pm 0.012$ & $0.326 \pm 0.019$ \\
\hline TSR & $1.00 \pm 0.11$ & $1.07 \pm 0.10$ \\
\hline
\end{tabular}




\section{Results \& Discussions: CH vs. THR (8)}
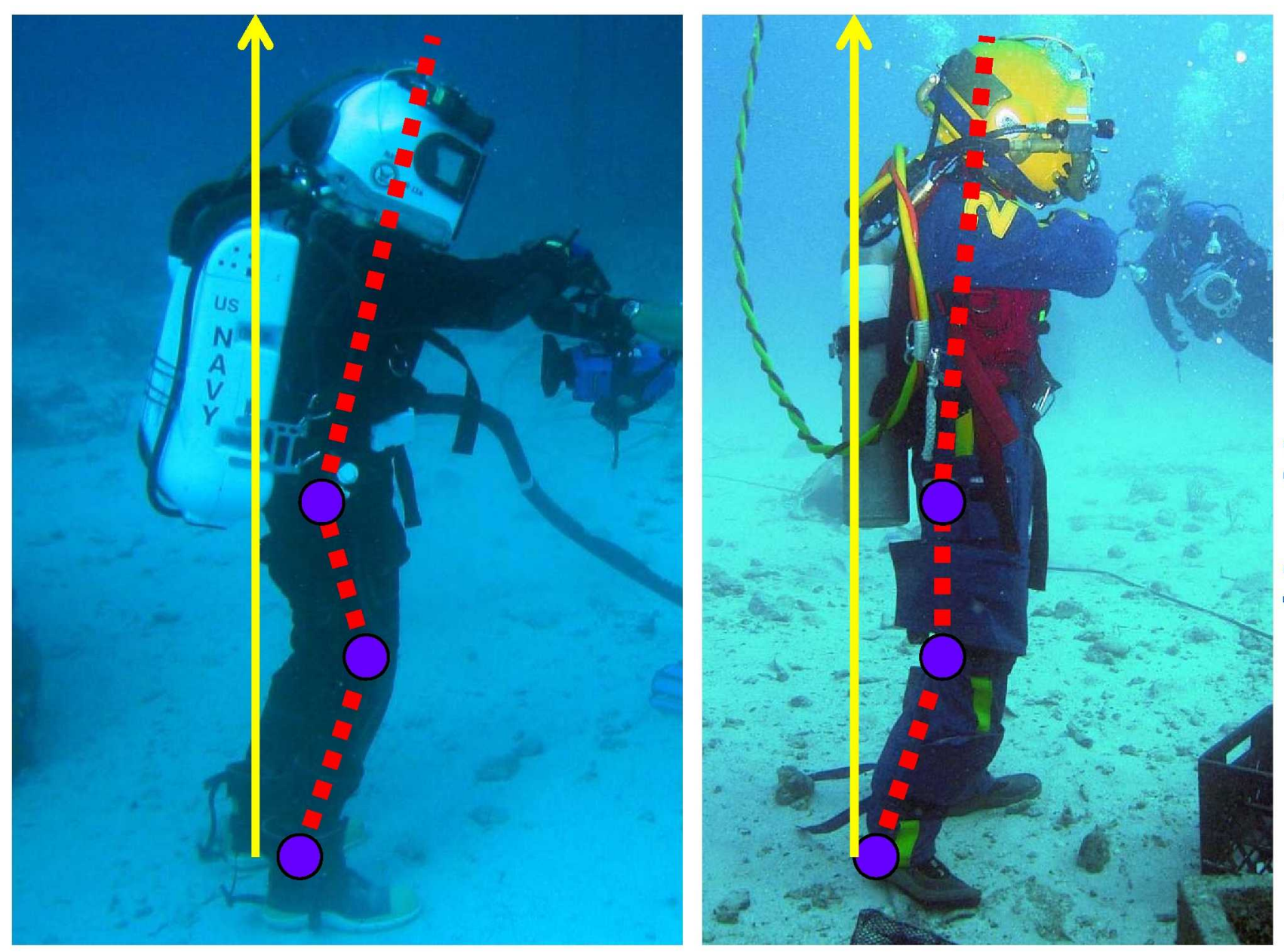

1. Lean via forward rotation about the ankle

2. Knee flexion

3. Forward waist flexion

Representative NEEMO photographs support the CG compensation mechanisms suggested 


\section{Results \& Discussions: CH vs. Height}

- $\mathrm{CH}$ against Height showed both direct and inverse correlations (50\%)

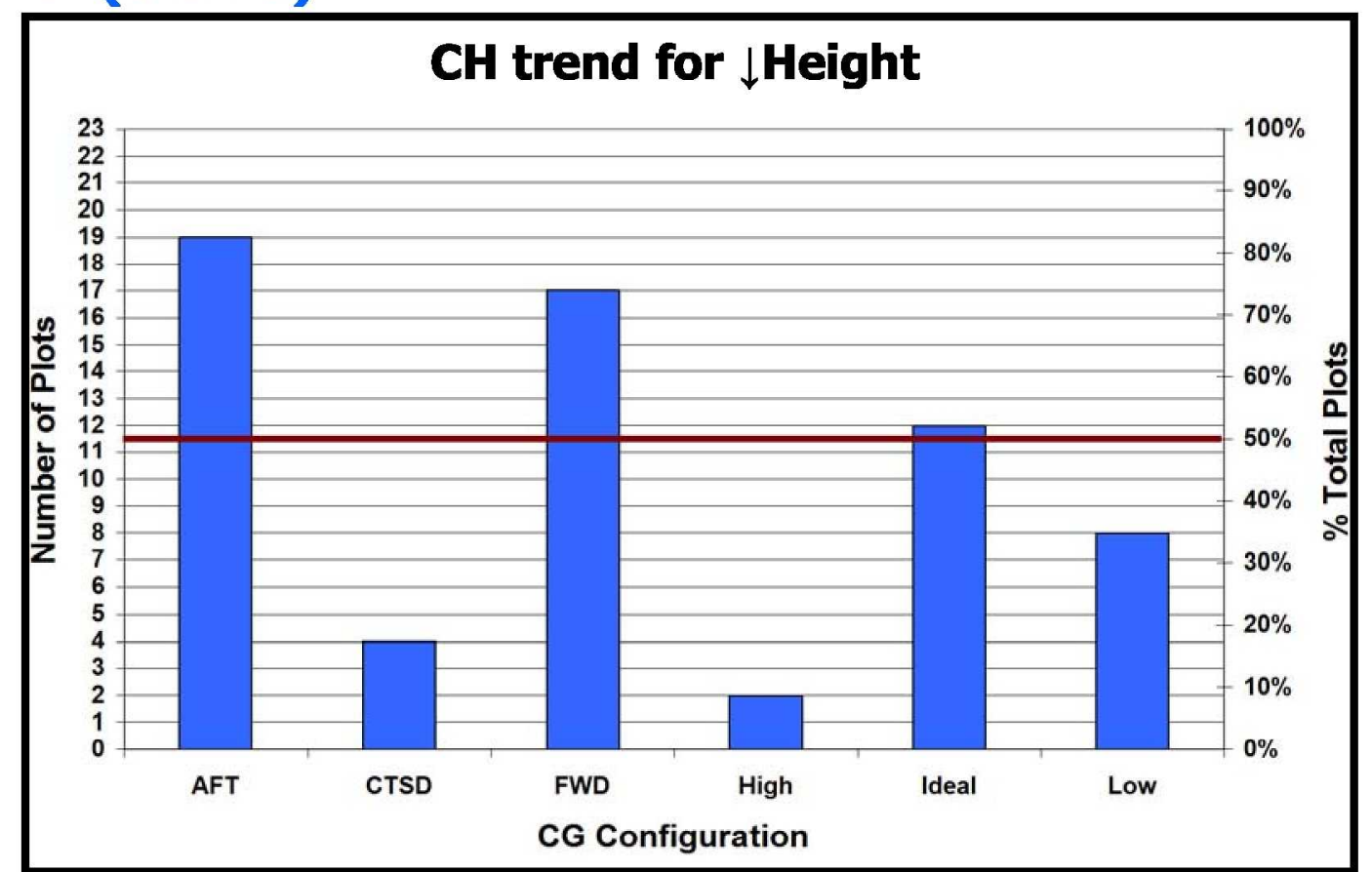

- Height of the subjects with the highest and lowest THR were within $2 \mathrm{~cm}$ of the average height, implying that height has less influence on performance than THR 


\section{Results \& Discussions: CH vs. Trunk Length (1)}

- Similar to $\mathrm{CH}$ vs. Height regressions, $\mathrm{CH}$ vs. trunk length regressions also showed both direct and inverse correlations

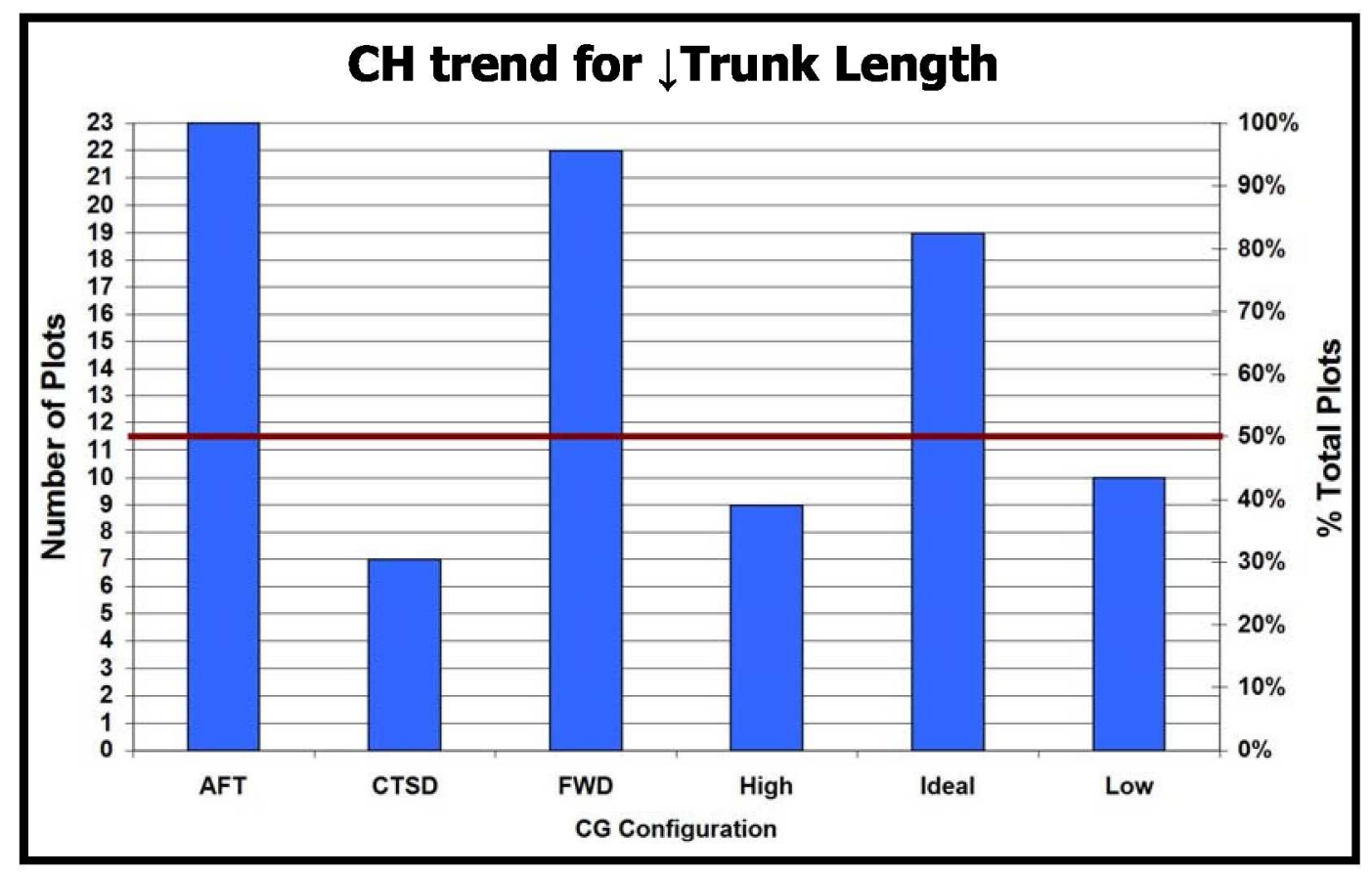

- However, results suggest trunk length may have greater influence on performance than height 


\section{Results \& Discussions: CH vs. Trunk Length (2)}

- The greater influence of trunk length on performance may be related to the relative differences in upper-body mass and MOI between the subjects with respect to the CG rig

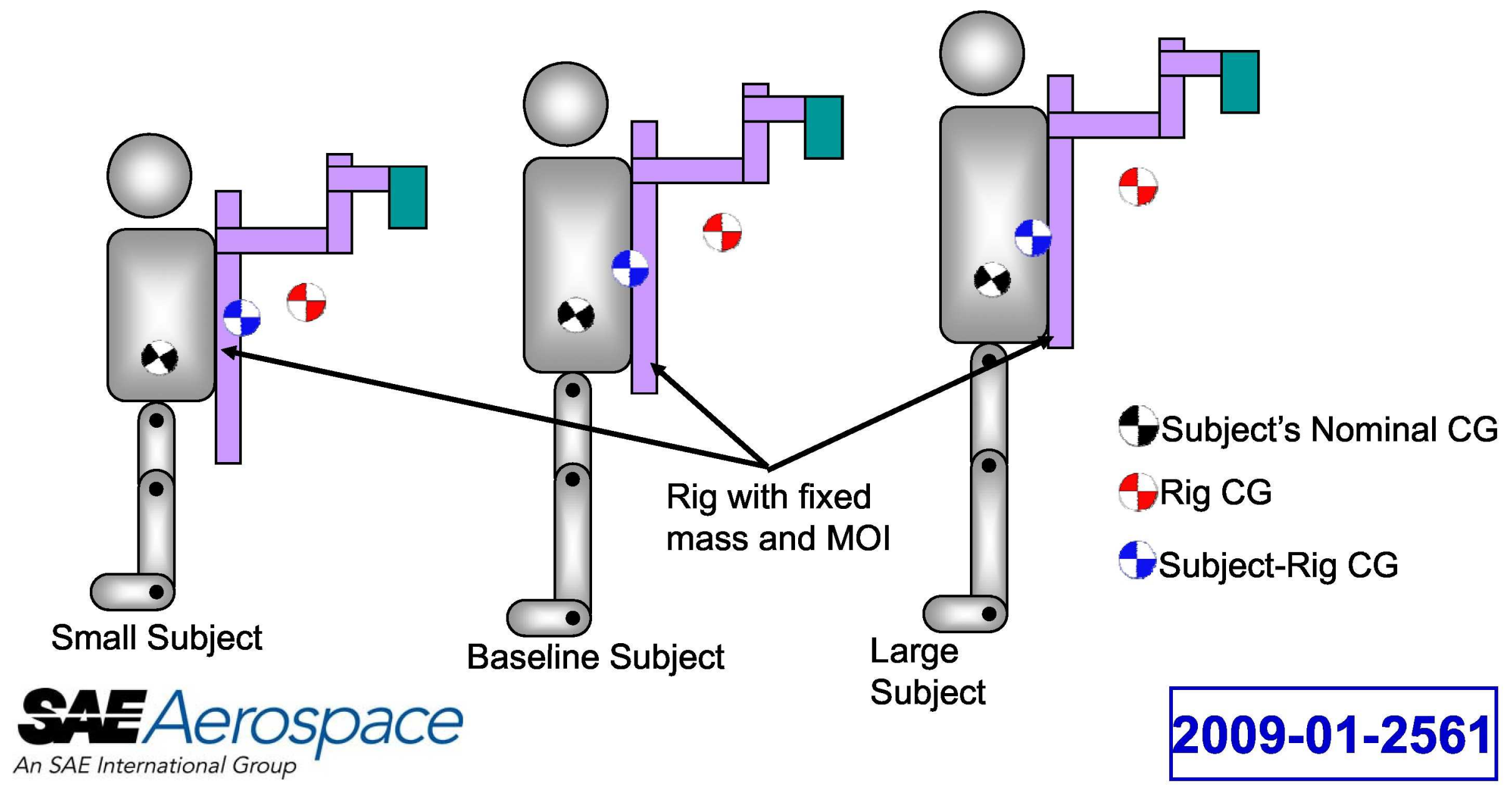




\section{Results \& Discussions: CH vs. Body Mass}

- For CH vs. body mass/weight plots, 4 of the 6 CG configurations showed an increase in $\mathrm{CH}$ with decreased mass/weight

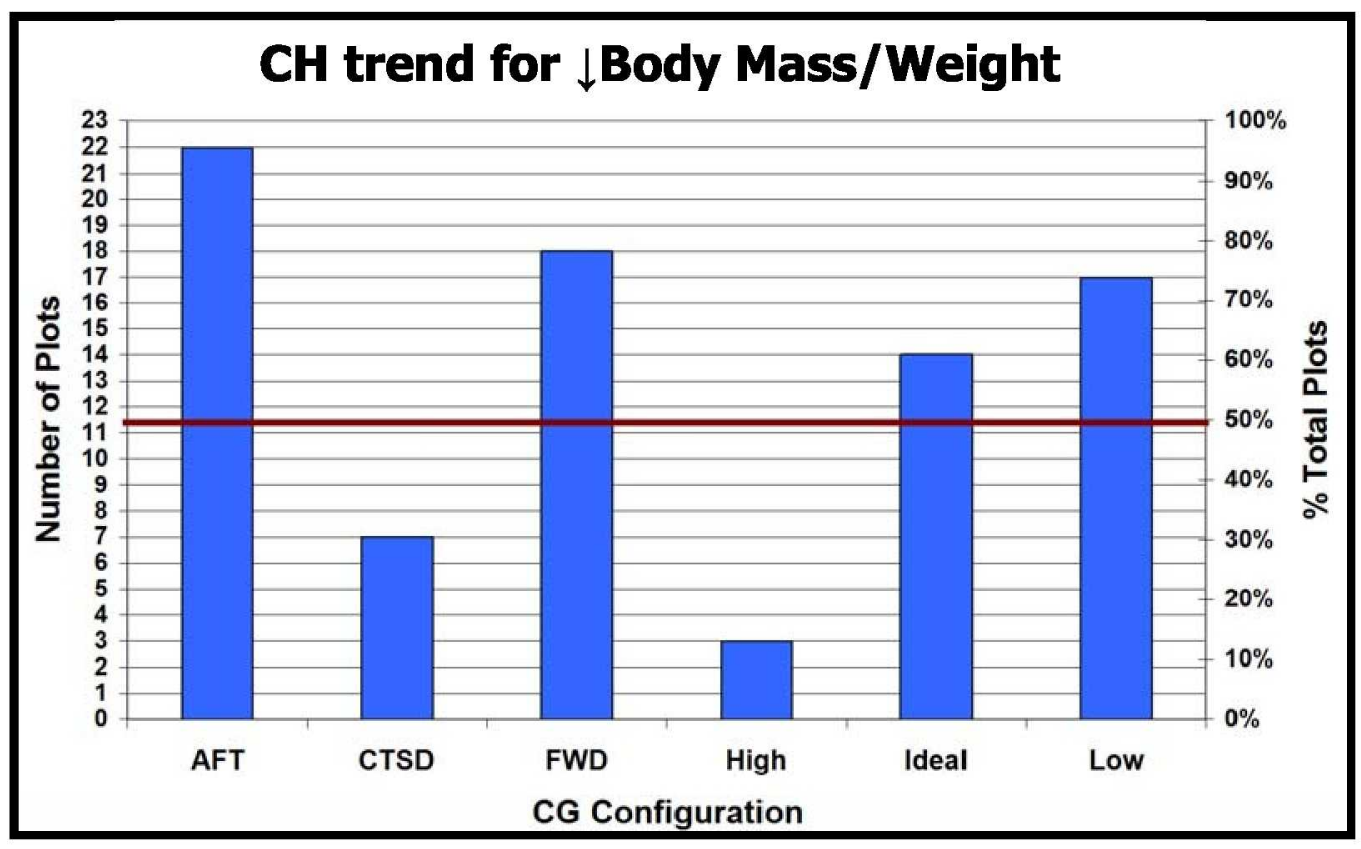

- Preliminary work by EPSP showed increased performance with increase suit weight in BWSS simulated lunar-g 


\section{Recommendations (1)}

- Validation of the EPSP "modified" CH scale by:

- Incorporating a non-subjective performance measurement system (e.g. metabolic rate measurement) or

- Subjective RPE (rating of perceived exertion) whenever direct metabolic measurement is not possible

- Analysis of $\mathrm{CH}$ data to verify the relationship between TSR and performance

- Assess the influence of standardized CG rig or PLSS design for a baseline subject (182.9-cm and $81.8-\mathrm{kg}$ male) can affect performance of subjects with varying anthropometrics 


\section{Recommendations (2)}

- Measures should be taken to account for changes in environmental and operational conditions per CHPRS guidelines

NBL and NEEMO regression comparison

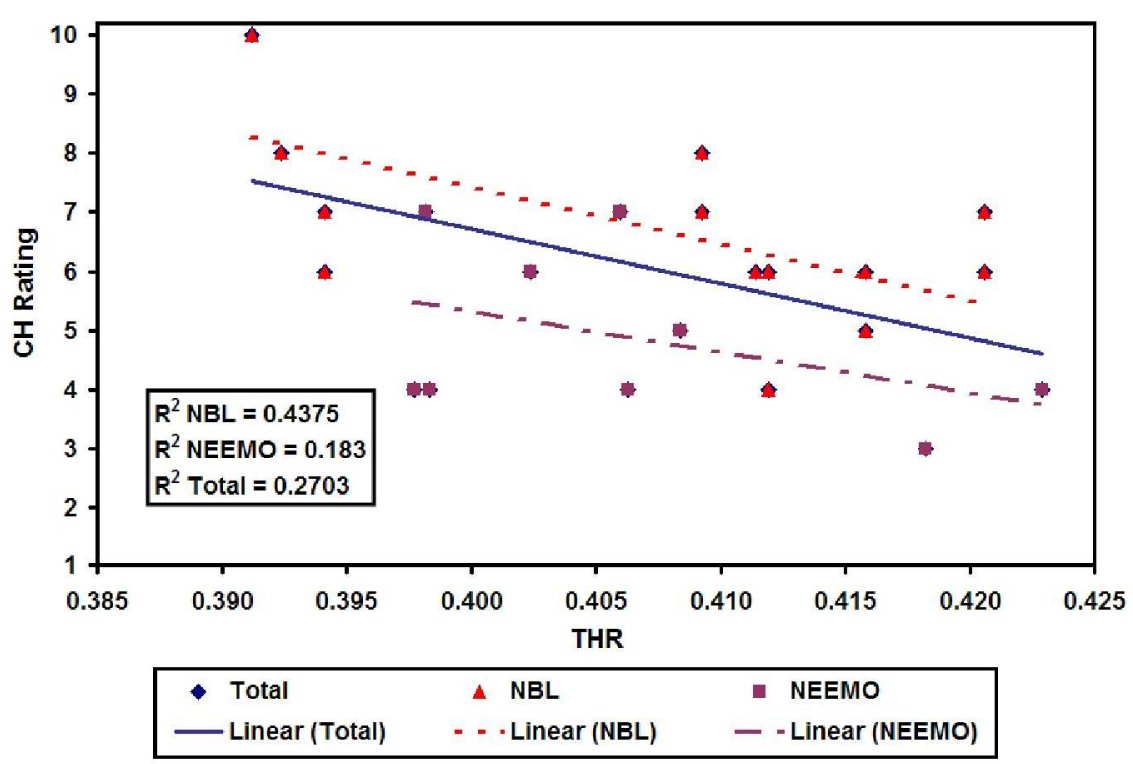

SAEAerospace

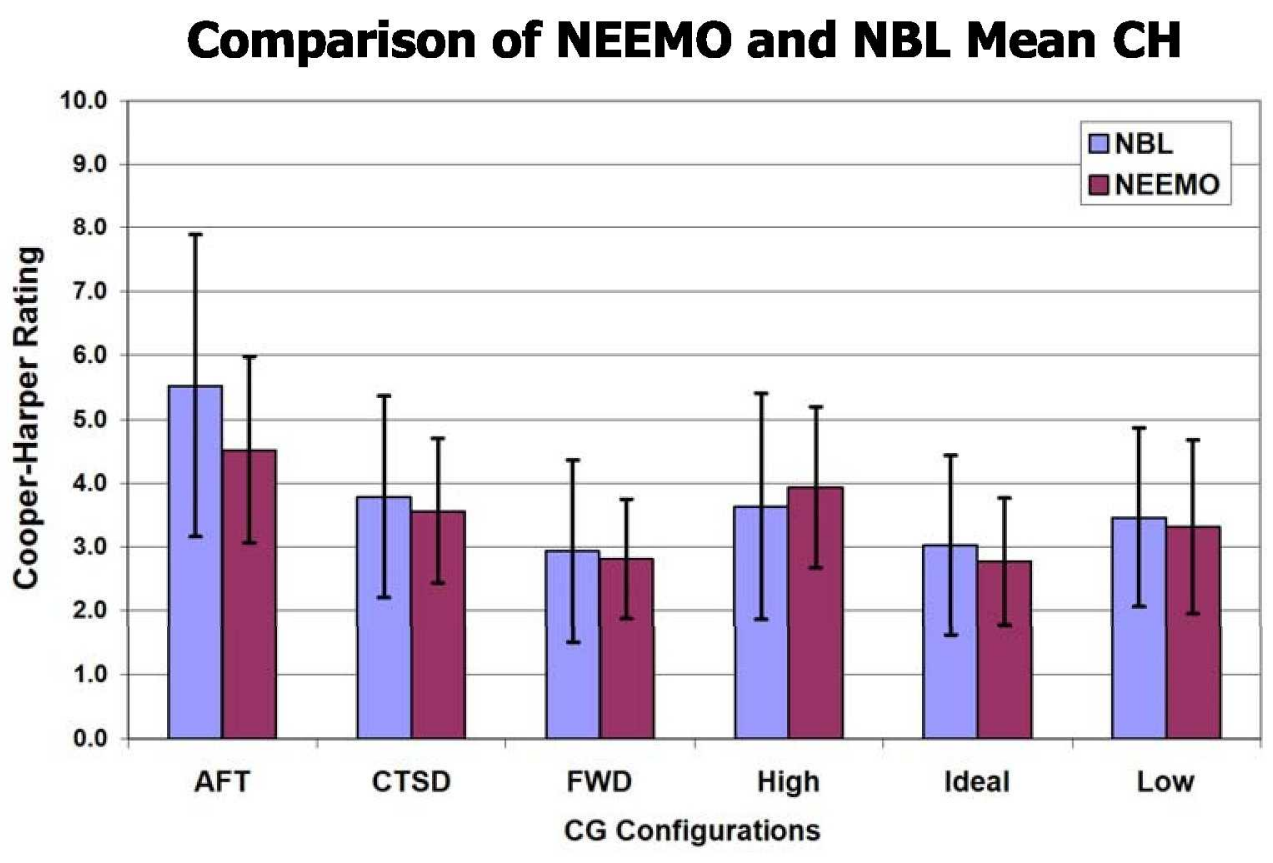

2009-01-2561 


\section{Recommendations (3)}

- When developing performance predictive regression models at the next phase of this work

- THR should be considered a main parameter and

- Body mass as a possible secondary parameter

- Further testing should be performed in prototype lunar exploration suits

- Suited test data and unsuited results, should be useful for future spacesuit design for optimum astronaut performance and safety 


\section{Conclusions (1)}

- Results support the hypotheses stated regarding the:

- Three mechanisms of CG offset compensation and

- Direct relationship between THR and human performance in simulated reduced gravity

\begin{tabular}{lc}
\hline $\begin{array}{l}\text { Anthropometric } \\
\text { Parameter }\end{array}$ & $\begin{array}{c}\text { Dominant } \\
\text { CH Trend }\end{array}$ \\
\hline$\downarrow$ THR & $\uparrow \mathrm{CH}$ \\
$\downarrow$ Height & $\leftrightarrow \mathrm{CH}$ \\
$\downarrow$ Trunk Length & $\leftrightarrow \mathrm{CH}$ \\
$\downarrow$ Body Mass & $\uparrow \mathrm{CH}$ \\
\hline
\end{tabular}




\section{Conclusions (2)}

- Literature presented to support the hypothesized inverse relationship between TSR and performance

- Results suggest some correlation between body mass and performance in simulated lunar-g

- Results to be used in future detailed logistic regression analysis of potential anthropometric factors that:

- may influence human performance in reduced gravity and

- drive future spacesuit design 


\section{Questions?}

\section{SAEAerospace}




\section{Backup Slides}

AAsEAEAerospace 


\section{Methods: NBL Tests}

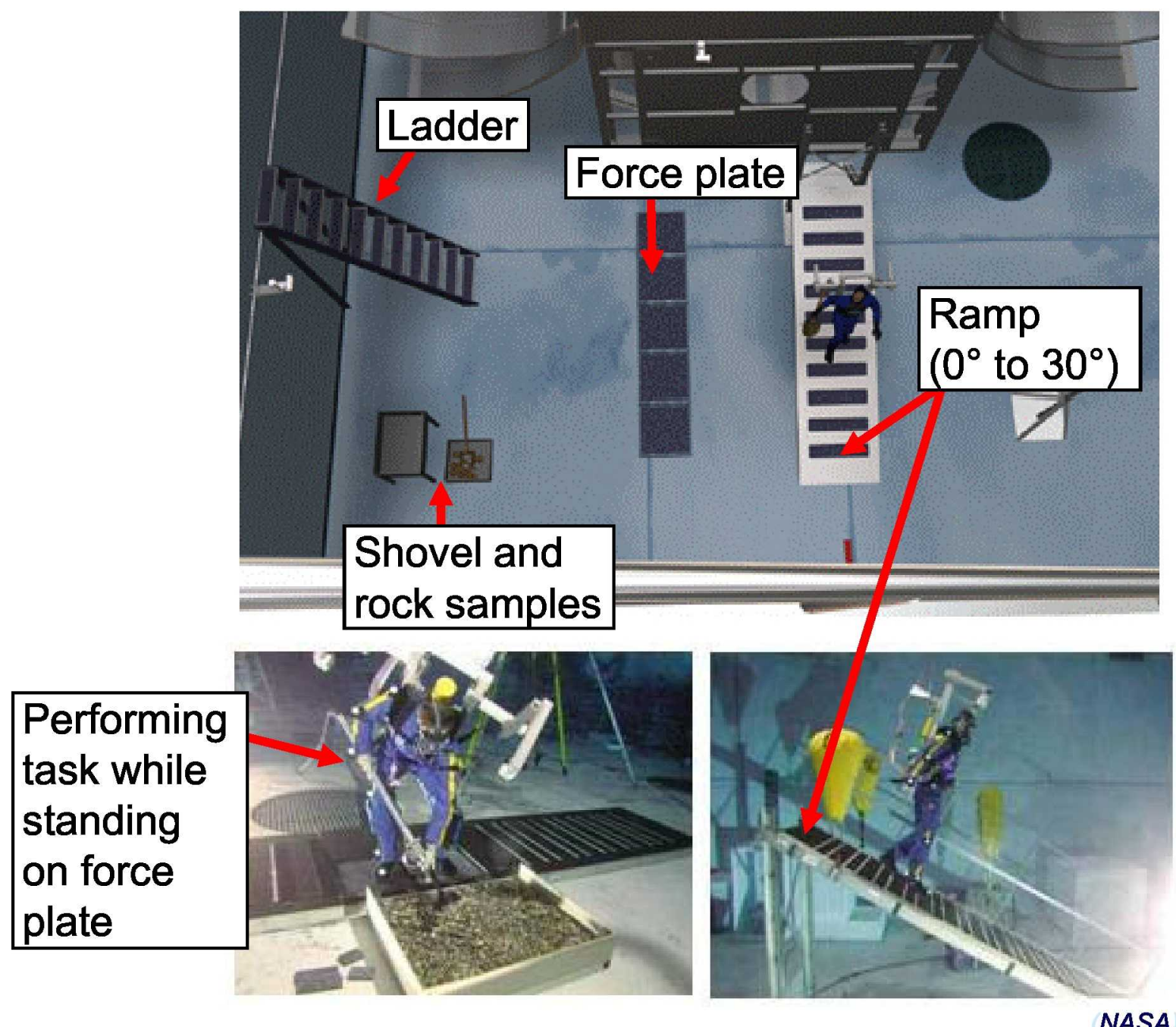




\section{Methods: NEEMO tests}
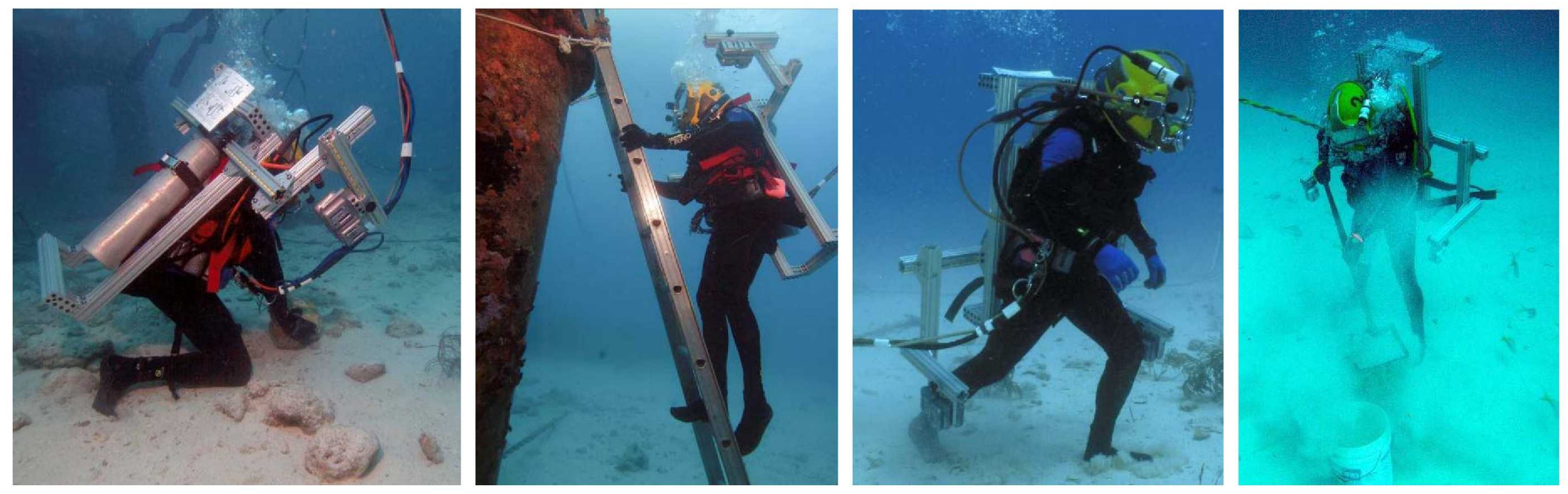

NEEMO tests performed using both specifically designed test equipment and preexisting structures near the NEEMO habitat 


\section{Results \& Discussions: CH vs. THR}

- Ward et al. suggested shorter legs allowed the master lifters to keep the weight closer to the body midline and to have less distance to move and get under the weight

- Further assessment of the anthropometrics presented by Ward et al. also showed the master lifters had lower TSR than the first class lifters

\begin{tabular}{lcc}
\hline \multirow{2}{*}{$\begin{array}{l}\text { Anthropometric } \\
\text { Parameters }\end{array}$} & \multicolumn{2}{c}{ Mean \pm SD } \\
\cline { 2 - 3 } Trunk Length $(\mathrm{cm})$ & $59.4 \pm 1.9$ & $56.4 \pm 2.2$ \\
Height $(\mathrm{cm})$ & $172.6 \pm 1.8$ & $172.8 \pm 7.7$ \\
Thigh Length $(\mathrm{cm})$ & $36.1 \pm 3.7$ & $39.3 \pm 3$ \\
Shank Length $(\mathrm{cm})$ & $36.1 \pm 1.8$ & $36.8 \pm 2.2$ \\
\hline THR & $\mathbf{0 . 3 4 4} \pm \mathbf{0 . 0 1 2}$ & $\mathbf{0 . 3 2 6} \pm \mathbf{0 . 0 1 9}$ \\
TSR & $\mathbf{1 . 0 0 \pm \mathbf { 0 . 1 1 }}$ & $\mathbf{1 . 0 7} \pm \mathbf{0 . 1 0}$ \\
\hline
\end{tabular}




\section{Backup Slides}

